\title{
Enhancing policy innovation by redesigning representative democracy
}

\author{
Sørensen, Eva
}

Published in:

Policy and Politics

DOI:

10.1332/030557315X14399997475941

Publication date:

2016

Document Version

Peer reviewed version

Citation for published version (APA):

Sørensen, E. (2016). Enhancing policy innovation by redesigning representative democracy. Policy and Politics, 44(2), 155-170. https://doi.org/10.1332/030557315X14399997475941

\section{General rights}

Copyright and moral rights for the publications made accessible in the public portal are retained by the authors and/or other copyright owners and it is a condition of accessing publications that users recognise and abide by the legal requirements associated with these rights.

- Users may download and print one copy of any publication from the public portal for the purpose of private study or research.

- You may not further distribute the material or use it for any profit-making activity or commercial gain.

- You may freely distribute the URL identifying the publication in the public portal.

\section{Take down policy}

If you believe that this document breaches copyright please contact rucforsk@kb.dk providing details, and we will remove access to the work immediately and investigate your claim. 


\title{
Enhancing policy innovation by redesigning representative democracy
}

\author{
Eva Sørensen
}

\section{Introduction}

Currently, public innovation is moving to the top of the agenda among decision makers in many Western liberal democracies, and the image of the public sector as intrinsically non-innovative (Downs, 1967) has gradually lost its grip. The belief in the possibility of enhancing public innovation was first voiced in the New Public Management (NPM) reform program of the 1980s and 90s (Hood, 1991), and with increasing force in the New Public Governance (NPG) reforms of the late 90s and 00s (Osborne, 2010). These reform programs have mostly focussed on how to innovate public services, however, while little attention is given to the question of how the public sector can enhance its capacity for policy innovation. The limited focus on policy innovation is problematic, not least in light of the growing distrust in politicians and disenchantment of democracy in many Western liberal democracies (Stoker, 2006; Norris, 2011). Enhancing the capacity of elected politicians to develop new policies that are able to solve problems that citizens perceive as important could contribute to solving this crisis for democracy.

This article takes its departure in the view that a comprehensive theory of public sector innovation must include a definition of policy innovation, considerations about how it can be enhanced, and thoughts on what barriers that must be overcome in promoting policy innovation. The aim of the article is to analyse the conditions for policy innovation in contemporary representative 
democracies. I start out by defining policy innovation and other related innovations in political life. Then follow a discussion of how political leadership, competition and collaboration can function as drivers of policy innovation and a description of barriers to policy innovation in traditional models of representative democracy. I move on to analyse two Danish case studies of recent experiments with policy innovation that seeks to enhance the space for collaboration between politicians and stakeholders, and the article concludes by identifying some of the challenges that face politicians and other actors who seek to improve the policy innovation capacity of representative democracy.

\section{Policy innovation and other related innovations in political life}

Although there are many competing definitions of innovations they generally agree that innovation involves the creation and realization of new ideas). Following Lawrence Green, et al, (2002, 9) innovation involves "doing something new i.e. introducing a new practice or process, creating a new product (good or service), or adopting a new pattern of intra- or inter-organizational relationship". Innovations can be new products but they can also be new organizational forms and procedures or new cultural images and role perceptions. Whether or not innovations provide added value, this is in the end always a matter of taste (Hartley, 2005). Therefore, it would be flawed to use the term 'innovation' as a normative qualifier for something good or beneficial. It is a descriptive term for a particular kind of change that can be evaluated positively or negatively by the involved parties. In this article, I aim to describe the ability of elected politicians in representative democracies to innovate policies and other aspects of political life. The normative underpinning of this research descriptive endeavour is the view that the future of representative democracy depends on its ability to accommodate the continuous production of political answers to emerging governance challenges. 
It should be noted that innovative changes in political life as well as in other phenomena are disruptive as well as productive. They produce something new but by doing so they undermine existing practices and common wisdoms (Sørensen and Torfing, 2011). As such, innovations create discontinuity in the form of creative disruptions of a phenomenon and are therefore distinct from changes that merely alter the quality or quantity of a given phenomenon (Osborne and Brown, 2005). Innovative changes can be either small and incremental or large and radical, but what unites them is that they involve the development and realization of new things, practices and perceptions that somehow break with the past. But what does it mean for something to be new? Innovation theory stresses that although innovations are sometimes based on the invention of something entirely new, they are more often the result of a pragmatic recombination of old and new elements, and imitation of innovative solutions from elsewhere through a process of adoption and adaptation (Rogers, 1995).

Seen through the lens of innovation theory, public innovation involves the development of new products in the form of new policies and services as well as new ways of organizing political life and public service provision, and new perceptions of what is normal and accepted behaviour among politicians, public employees and users of public services. These innovations are outcomes of processes of creative destruction of the given and an inventive combination and adaption of new and old elements of public governance (Sørensen and Torfing, 2011). As evidenced by a number of studies, innovations in governance tend to be interrelated and one kind of innovation is often followed by others trigger another kind of innovation (Roberts and Bradley, 1991; Ansell and Torfing, 2014). Hence, organizational and procedural innovations often trigger product innovations and changes in the role images of the involved actors and vice versa. Therefore an analysis of policy 
innovation must include a larger analysis of innovations in political life defined as the interrelatedness between policy innovation and innovations in the formal and informal institutional rules and norms through which these policies are produced as well the cultural images and role perceptions attached to these rules and norms. The three interrelated aspects of political life that can be made subject to innovation are listed in table 1 and elaborated in the following sections.

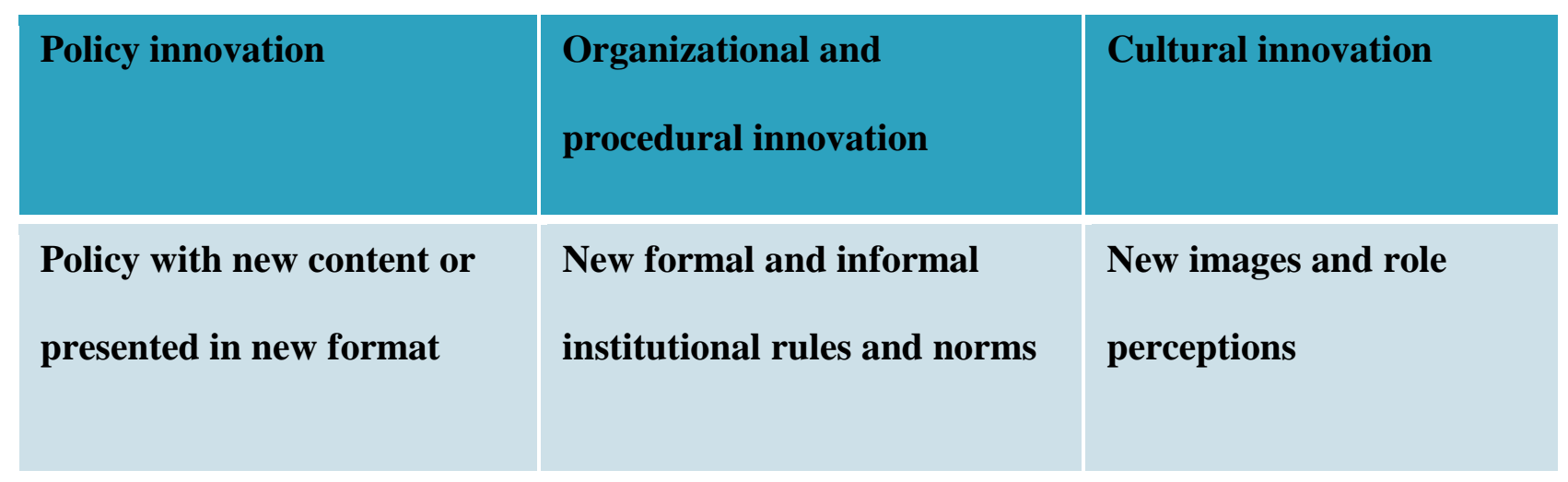

Table 1: Three interrelated forms of innovation in political life

\section{Policy innovation}

A policy innovation provides changes in the content or form of a policy (Polsby, 1984). The content of a policy is innovative to the extent that it offers a new definition of a political problem, provides a new political vision for the political community, and/or proposes a new set of political goals and strategies. Since policy innovation involves a high degree of normative contestation and positioning between actors with different perspectives, ideas, views and interests, political innovations processes tends to be ridden by conflicts. Conflicts are particularly likely in the case of policy innovations that challenge existing hegemonic political positions or address heavily politicized policy issues (Howarth and Torfing, 2005). Cases in point are new policy initiatives in the area of gun control in the US, and integration reforms in the Netherlands. In less conflict ridden policy 
areas, policy innovations can pass smoothly through the political process. As pointed out by John W. Kingdon (1984), however, it is not always predictable whether or not a policy innovation will meet resistance or travel quietly through the political process. The faith of a new policy depends to a considerable degree on whether or not a strong political entrepreneur or leader is able to identify and exploit a window of opportunity through skilful timing and alliance building. The same observation is made by Nancy C. Roberts and Paula J. King (1996) in their seminal book on policy transformation where they stress the importance of strategic political leadership for overcoming political resistance against new innovative policy contents as well as for creating support and ownership among political key actors.

Policy innovation does not only involve the development of new policy contents, however. The format of a policy can be innovated too. The format given to a policy is determined by habit as well as by its function in the governance process. Traditionally, policies have mainly taken the form of laws and regulatory documents formulated in a complex, formal, technocratic and codified language that was well suited for public professionals but not for lay people. However, as political authorities increasingly seek to mobilize a wide variety of social actors in solving governance tasks, there is a growing need for policy formats that reach a wider audience. Policies aiming to promote healthy living must be communicated to those citizens who need to change their way of living, and in the case of crime prevention target audiences are often local communities who can assist in creating safe environments and other local actors who are in in a position where they can help those who are about to choose a bad route in life. In those and other policy areas the impact of a policy depends to a considerable degree on whether or not it is made subject to public debate in the traditional mass media as well as in the new social media. Therefore, it seems relevant for policy makers to develop policy formats that fit the emerging forms of political communication better than do the traditional 
technical codified policy documents that are difficult to grasp by relevant and affected audiences (Savigny, 2002).

\section{Organizational and procedural innovation}

Policy innovations can also consist in new ways of organizing and processing policy making (Damanpour, 1991). Although political life in Western representative democracies at least formally tends to be organized around the same ideal typical organizational principles, there are huge variations between countries (Lijphart, 1977). Furthermore informal rules and norms vary between countries and over time. These variations are results of small and large changes in the organizational set up and procedures for policy making in the individual countries. At the aggregate level the institutional changes can be seen as an ongoing multi-directional innovation of representative democracy, which is driven by small and large political battles as well by efforts to cope with changing societal conditions. The intensity of the innovative endeavours varies over time. Periods of relative stability are interrupted by periods of radical change. Recent studies (Borins, 2014; Cain, Dalton and Scarrow, 2003; Smith, 2009) indicate that we are in a time of change. Institutional reforms in the institutional set up of representative democracy are proliferating in many Western liberal democracies aiming to overcome growing distrust in politicians and the general disenchantment of representative democracy (Stoker, 2006; Norris, 2011). Many of the institutional reforms are introduced at the local levels of governance, examples being deliberative forums in Copenhagen, user boards in Chicago and participatory budgeting in Brazil. There are also innovations, however, that are directed towards national and transnational levels of governance one prominent example being the Open Government reform program in the US (US-Government, 2012). Although the present climate among political decision makers creates a momentum for organizational and procedural innovations, there are path-dependent forces at play in political life 
that hampers change. Among these forces is a general unwillingness of those in power at a given point in time to support institutional changes that will destabilize their position (Roberts and Bradley, 1991; Pierson, 2000). Accordingly, organizational and procedural innovations often result in no more than symbolic acts or isolated experiments that do not have a lasting or profound impact on the form and function of public policy making.

\section{Cultural innovation}

Finally, policy innovation can take the form of changes in the cultural images and role perceptions of political actors. A culture can be defined as a set of tacit norms and guidelines for how to act and interact in a certain context (Shein, 1992). These norms and guidelines refer to a more or less coherent logic of appropriateness that specifies how an actor can behave and interact in a meaningful, normal and legitimate way in specific situations. Drawing on this definition, a political culture represents a constellation of role positions that accommodate but also restrict politicians, public administrators, citizens, private firms and voluntary organizations in their exercise of political agency (Torfing, et al, 2012, 146). Political cultures are highly dynamic and ambiguous, that are constantly made subject to innovation. Small scale changes happen all the time as a result of ongoing efforts to cope with the internal ambiguities between different rules and norms within any given culture (March and Olsen, 1989), and reactions to contextual changes such as adjustments in the formal institutional setting or discursive shifts in society e.g. the current decline of trust in formal authority (Kramer and Tyler, 1996). Large scale changes in political culture result from paradigmatic shifts that combine new and old cultural signifiers and artefacts in creative ways. A recent example is the NPM reform program that introduced a new image of the public sector as a market for public service provision that included a reinterpretation political role positions: politicians was no longer sovereign rulers but a Board of Directors, the bureaucrats became 
strategic managers, citizens stepped into the role as costumers, and private firms and NGOs became public service providers (Torfing et al, 2012). Cultures do not change easily, however, as witnessed by the fact that the NPM paradigm has not been able to completely push aside traditional cultural images and role perceptions. The routinized practices born out of tradition tend to prevail, and people are generally reluctant to reinterpret their perception of what is meaningful, normal and acceptable behaviour for themselves and others in a given context. Role images provide a road map that reduces complexity and explicates what an actor should do and not do and what they can expect from others (Sørensen, 2006). Without this road map the world appears as unsafe and dangerous. Therefore, the willingness of actors to engage in cultural innovations depends, among other things, on the degree to which a new attractive roadmap is in sight. This also counts for a political culture where the willingness of political actors, and not least the politicians, to step into new roles depends on whether they can see a new promising future for themselves on the horizon.

\section{Three drivers of policy innovation}

As we have seen above, policy innovation is closely related to other innovations in political life. Before we look more closely at the interrelatedness between policy innovation and other political innovations, I will seek to clarify what counts as key drivers of policy innovation. Drawing on policy analysis and innovation theory, it is possible to identify three drivers of policy: leadership, competition and collaboration.

Both innovation theory and theories of public policy making points to entrepreneurial leadership as innovators (Schumpeter, 1946; Weber, 1947), but a new understanding of the role of leadership in promoting innovation is emerging in both disciplines. In innovation theory, the role of business 
leadership is increasingly seen as that of getting others to innovate (Deschamps, 2008; Bel, 2009), and policy analysts such as John W. Kingdon (1984) have pointed out that what political leaders do is to set agendas that call for innovation, and to recruit, motivate, steer and support political, administrative, professional and social actors who innovate. Drawing on recent literatures four roles can be assigned to leaders of policy innovation (Sørensen, 2006; Ansell and Gash, 2012): 1) the convenor who brings selected actors to the table around a specific topic; 2) the facilitator who accommodates actors in their efforts to innovate; 3) the catalyst who creates windows of opportunity that calls for new initiatives; and 4) the participant that allow leaders to test, develop and communicate their ideas and viewpoints in debates with those who innovate in order to become wiser and to make sure, that the new innovative policies do not deviate radically from the norms and values among those who are to authorize the innovative policy outcomes (Sørensen, 2006). In order to fulfil these roles, however, political leaders need strong bargaining powers and strategic skills. They need what Christopher Hood (1986) calls NATO resources referring to Nodality, Authority, Treasure and Organization. Moreover, they need the rhetorical skills it takes to legitimize the innovations in the eyes of the larger public and to persuade relevant audiences of the potential benefits that can be achieved if they are willing to engage in the development of new policies in the face of what is at a given point in time perceived as a pressing policy issue also denoted a burning platforms (Willner, 1985). An example of how burning platforms can be used to legitimize innovation is how politicians in many countries have used the results of the PISA program for international student assessment formulated by the Organization for Economic Co-operation and Development (OECD) to put educational reforms on the political agenda and put pressure on relevant actors to suggest appropriate policy solutions. This example also illustrates the point made by Robert Tucker (1995) that not only politicians but also other actors, e.g. independent policy 
agencies such as the OECD, can construct create a window of opportunity for policy innovation through the construction of pressing policy problems.

Competition is another important innovation driver celebrated by traditional theories of innovation and political science (Schumpeter, 1946; Sartori, 1987). It is a key assumption in innovation theory that competition between business firms stimulates the development of new products and production methods (Nickell, 1996), and theories of representative democracy view competition between politicians on Election Day as an important force behind the formulation of new innovative policy programs (Polsby, 1984). Hence, competitive pressures motivate and encourage actors to embark on the troublesome, costly and hard journey it is to develop something new. In illustration, markets characterized by intense competition are more innovative than markets with limited competition (Sharpe and Currie, 2008). For the same reason, the production of new innovative political programs is predominantly taking place in political parties that have experienced a drop in voter support (Hersey, 2014). Recent developments in innovation theory and theories of public governance increasingly note, however, that competition can also hamper innovation because it delimits the exchange of knowledge and ideas, prevents resource pooling and increases the risk of failure (Teece, 1992; Nambisan, 2008). Competition is therefore increasingly seen as a two edged word: it motivates actors to innovate but it hampers their efforts to do so.

Recognizing that neither leadership nor competition is sufficient to ensure innovation has turned the focus of attention of those studying private and public innovation towards the question of how collaboration can contribute to the promotion of innovation. Theories of private sector innovation are increasingly interested in the role of business clusters, and production chain networks for promoting innovation (Edquist and Hommen, 1999; Nambisan, 2008). Moreover, there is a growing 
interest in how collaboration between firms and customers can work together in an attempt to develop new innovative products (Von Hippel, 2005). In public innovation research, the New Public Governance (NPG) (Osborne, 2010) paradigm views collaboration as an invaluable factor in promoting public innovations in the face of the growing complexity of public policy problems, and comprehensive empirical studies support this view (Borins, 2001, 2014; Agger et al, 2015). Collaboration between different types of actors is valuable because it can spur the creative destructions of existing world views and notions of what is possible, the formulation of new creative ideas, ways of transforming these ideas into things that work and are diffused to relevant audiences. In other words, collaboration has something to offer in all the phases of an innovation process (Freeman, 1991; Dente, Bobbio and Spada, 2005).

The degree to which collaboration leads to the development of new policy ideas, however, does not depend on the ability of the involved actors to reach a consensus. The ideas that emerge might result in contestations that cannot be overcome. Nevertheless, the new perspectives and ideas that have been articulated can inspire the involved actors in their on-going attempts to develop new policies in other contexts (Gray, 1989; Roberts and Bradley, 1991). However, a rough consensus or negotiated agreement is reached, collaboration can enhance the capacity for policy realization because it enhances the political ownership and commitment among those who have participated in the collaborative process in ways that accommodate the political decision making and implementation processes. Finally, collaboration promotes policy diffusion if it recruits interested parties and opinion-makers as ambassadors for a new policy innovation. An example of a policy innovation process where collaboration played a productive role is the transition from a welfare policy to workfare policy in Danish labour market policy in the 1990s (Torfing, 1999). This transition was a result of intensive collaboration between a wide range of public and private 
stakeholders. Collaboration can also sometimes block policy innovation if some of the participating actors lack the motivation to question existing policies and ways of working in political life. This danger is considerable in the case of weak political leadership (Roberts and King, 1996) or if there are few pressures to develop new policy programs due to a low level of political competition (Bullinger et al., 2010).

In conclusion, policy innovation is driven by a combination of political leadership, competition and collaboration (Hartley, Sørensen and Torfing, 2013). Political leadership and political competition that spur collaboration are decisive for promoting policy innovation, and so are collaborative endeavours and competitive procedures that motivate political leaders to call for political change. Political leaders with the courage and incentives to launch new political ideas developed in collaborative policy arenas can also trigger efforts to innovate policies among opposition parties and other political actors who experience that they are losing the political initiative. It is a difficult task, however, to design the right configuration of innovation drivers for democratic policy making. If the level of political competition becomes too fierce there is no willingness to collaborate, but if the competitive pressures are weak, the political actors will have few incentives to put policy innovation on the political agenda. In that case both political leaders and collaborative arenas will tend to contend themselves with the status quo. Therefore, the policy innovation capacity of representative democracies depend, to a considerable extent, on the extent to which public authorities take on the task as designers of productive conditions for policy innovation.

\section{Barriers to policy innovation in traditional models of representative democracy}


In light of the above call for a combination of the three drivers of policy innovation, it must be considered to what extent and how the political systems in Western liberal democracies provide such a balance. At a general level of analysis, I find that the formal policy making structure and the cultural images and role perceptions advocated by mainstream models of representative democracy favour political leadership and competition more than collaboration. Empirical studies show, however, that political life in Western liberal democracies involves a high degree of more or less informal interaction between political, administrative and social elites (Lindblom, 1965; Schmitter, 1974). The informal character of these interactions, the fact that they tend to involve political, administrative and social elites rather than relevant and affected stakeholders, and that the purpose tends to be bargaining rather than collaborative policy innovation, indicate that there is a considerable potential for enhancing policy innovation in representative democracies by improving the conditions for collaboration between politicians and relevant and affected stakeholders. Therefore, we need to clarify to what extent and how the establishment of arenas for collaborative policy making can enhance the policy innovation capacity of representative democracy. In answering this question, first step is to identify some of the potential barriers to policy innovation in models of representative government. These barriers are summarized in table 2 .

\begin{tabular}{|l|l|l|}
\hline Policy barriers & Organizational and & Political culture barriers \\
\hline procedural barriers & & \\
\hline Policy contents focus on & Policy making is mostly & Traditional cultural \\
\hline authoritative regulations & organized as an in-house & images of how policy \\
\hline rather than on mobilizing the & activity that only involves & making is to take place \\
\hline problem solving capacity of & politicians and administrators & discourage interaction \\
\hline
\end{tabular}




\begin{tabular}{|l|l|l|}
\hline relevant social actors & with external actors. \\
\hline $\begin{array}{l}\text { Policy formats rarely target } \\
\text { those street level bureaucrats }\end{array}$ & at a very late stage in the & perceptions define \\
\hline and citizens who are to & policy process & politicians as solitary \\
\hline implement the policy & & policy makers \\
\hline
\end{tabular}

\section{Table 2: Potential barriers to policy innovation}

In representative democracies politicians and other public authorities tend to focus policy contents on what they themselves can do to solve policy problems. At national levels of governance, policies often consist in passing new laws and regulatory rules and allocating funding. As a consequence, the format of new policies is often technical in kind and directed towards regulators such as lawyers and policy designers designed to inform stakeholders such as street level bureaucrats and affected publics. This approach to policy making is increasingly problematic because it fails to take into account the increasing de-statification of policy making that is driven by a growing complexity the policy problems that are on the political agenda (Jessop, 2004). Examples are global warming, the growth in lifestyle related illnesses, and immigration problems. Many of these problems can only be solved through the mobilization of the resources and energies of a wide range of social actors, and policies that in content and format fail to mobilize these actors are likely to fail.

When policy making is mostly organized as an in-house activity among politicians and administrators at national and local levels of governance, there is little room and occasion for dialogue, knowledge exchange and collaboration between politicians and relevant and affected stakeholders (Carstensen and Bason, 2012). It should be noted that most representative democracies 
do have mechanisms that allow external actors to contribute to policy innovation. At national levels of governance, Expert Commissions and Think Tanks provide policy recommendations and at local levels of governance user boards and local citizen committees are sometimes involved in policy innovation (Mayo and Hollander, 1991; Goodin and Dryzek, 2006). However, since politicians are rarely directly involved in these policy innovation debates, they often end up selecting recommendations that fit their pre-given policy positions, or fail to hear about the outcomes of these debates. There are also hearings that allow relevant interest groups and institutions to comment on new political reform programs but their comments arrive at a late stage in the political process where the politicians have already committed themselves to a certain view point, or a negotiated agreement has been made and cannot be undone without huge political costs.

Deeply engrained in the political culture of representative democracies is that there should be a safe distance between public authorities and relevant and affected social actors. The purpose is twofold: to ensure that politicians and public administrators do not fall victim to pressures from strong private interests (Sartori, 1987), and to protect civil society actors from being co-opted by public authorities (Bang, 2003). This fear of clientilism and totalitarianism has resulted in a tendency to stigmatize all forms of interaction between politicians and relevant and affected stakeholders rather than institutionalizing it in ways that strengthen the legitimacy and governance capacity of the political elites and accommodates collaborative policy innovation. The role perceptions in traditional models of representative democracy represent another cultural barrier to collaborative policy innovation. Politicians are portrayed as sovereign rulers with sufficient capacity and full responsibility for developing new innovative policies while bureaucrats and seen as rule and order following policy implementers, and citizens, private businesses and voluntary organizations are passive recipients of policy solutions (Torfing et al., 2012). These role images overlook the fact that 
politicians are rarely in a position to define and solve policy problems on their own and that collaboration with relevant and affected stakeholder could enhance their capacity to develop new innovative political visions, goals and strategies that are able to produce added value.

\section{Lessons from experiments promoting collaboration in policy innovation}

Studies of experiments seeking to promote collaborative policy innovation between politicians and relevant and affected stakeholders appear as a promising way of clarifying to what extent the introduction of collaborative governance arenas can contribute to promoting policy innovation by shifting the balance between political leadership, competition and collaboration. We see a surge of such experiments in Denmark. Most of them take place in the municipalities but some are also found at the national level of government. Two of these experiments are particularly interesting in this context. First of all, their specific purpose is to develop new problem definitions and policy solutions by bringing together relevant and affected stakeholders. Second, rather than staying at an arms-length distance as is often the case, a number of politicians are directly involved in the collaboration process. Third, the experiments provide amble time and space for comprehensive collaboration. Finally, it seems relevant to choose a case of local and national policy innovation, respectively because it allows for considerations regarding differences in the conditions for policy innovation at different levels of government. The two case studies will first of all clarify if the collaborative governance arenas succeeded in developing a new innovative policy content and policy format. Moreover, I will analyse how the collaborative policy arenas contributed to overcoming some of the barriers to policy innovation described earlier. Finally, I discuss to what extent the experiments managed to establish a productive balance between political leadership, 
competition and collaboration, and whether differences between the conditions at local and national levels of government can explain differences between the two cases.

\section{Collaborative policy innovation in Albertslund Municipality}

In 2010, Albertslund municipality initiated a project aiming to develop a new innovative citizen involvement policy through the establishment a collaborative policy arena. A colleague and I observed the process from beginning to end over a two year period. The data consisted of observations of meetings and other events, document studies and research interviews with the involved actors. The study is reported in detail elsewhere (Agger and Sørensen, 2014). The project was initiated by the City Council who decided to form an ad hoc committee composed of six politicians, six citizens and three public administrators as an alternative to developing the policy in a standing political committee, which was normal practice. The committee was given one year to prepare a policy proposal.

In the course of this time, the committee managed to develop an innovative policy content that redefined the overall purpose of citizen involvement in Albertslund. Emphasis was put on citizen involvement as a means to innovate public policy and services rather than as a toll for enhancing democracy. The new innovative policy content was relatively vague, however, and took the form of a broad political vision rather than a commitment to concrete political goals and strategies. Also the policy format way innovated so as to reach new audiences that the public authorities themselves. It took the form of a short policy pamphlet that rephrased the problem definition and aim that was originally commissioned. The policy pamphlet was formulated in a language suited for broad distribution among municipal employees and citizens and it was supplemented by videos of interviews with citizens about the benefits of citizen involvement. In addition, a manual was 
produced describing methods for citizen involvement to be used by the employees. The organizational set up and procedures used in the process also took new forms. Instead of running a series of traditional meetings with a fixed agenda and structured debates between the members, the committee decided to invite different policy experts to their meeting and to host an innovation camps and a workshop with relevant and affected stakeholders in addition, and minutes were exchanged with mind maps. As a result of this new way of working, the relationship and role perceptions of the participating citizens, politicians and administrators gradually changed. The citizens began to see the municipal actors as collaboration partners and themselves as capable coproducers of policy ideas. The politicians on their side found that they could develop new ideas in discussion with citizens and other relevant stakeholders, and found that this was more satisfactory than defending fixed policy positions. Also the administrators redefined their role positions. They gradually changed from controllers to participants in the discussions. The politicians in the City Council were invited to participate in the innovation camp that was held half way through the process. When the work ended, the ad hoc committee presented the policy proposal at two meetings in the City Council, and the proposal was passed without changes. The on-going communication over the one and a half years the policy innovation process lasted can contribute to explaining the low level of conflict and dispute in the City Council when the new policy was passed.

\section{Collaborative policy innovation in The Ethical Council}

In 2011 a Danish think-tank called The Ethical Council, initiated a collaborative policy innovation process aiming to develop policy advice to the Danish parliament regarding how to reduce the use of force in psychiatric treatment. A colleague and I observed the one year long policy process. In line with the Albertslund study, the data included observations of meetings and other events, 
document studies and research interviews with the involved actors (See Sørensen and Waldorff, 2014 for more detail). The Ethical Council was formed by the Danish national parliament in 1987, and the goal was to advise the Danish Parliament on policy matters involving ethical dilemmas related to science. The Council is headed by a board appointed by the parliament and different ministries. The Board wanted to spur more interest in the policy advice they gave among the politicians as well as among other relevant and affected stakeholders, which they found increasingly difficult. The basic idea was to bring politicians and relevant and affected stakeholders together in a shared effort to map and explain the use of force in the treatment of psychiatric patients and to suggest ways to reduce it. The experimental policy process led to the formulation of an innovative policy content and form, a new organizational and procedural set up for policy making, and new role perceptions among the involved actors.

The content of the policy that was developed was innovative in the sense that it rejected the existing hegemonic idea that the use of force in psychiatric treatment was resulting from financial constraints and insufficient legal regulation. It was concluded that use of force was primarily a product of the culture in psychiatric institutions, and efforts to change things should therefore seek to change the culture. Moreover, a new policy format was developed. The Ethical Council concluded that the new innovative problem definition and policy suggestions increased the importance of reaching a broad variety of relevant and affected stakeholders such as the patients and employees in psychiatric care as well as the politicians. Therefore, the traditional policy brief was supplemented with easy to read folders and videos that were distributed to the employees in psychiatric care. The Ethical Council also changed its organizational set up and procedures for this particular occasion. Normally the Council developed policy proposals in the secretariat based on discussions between the Board members, and only now and then did they invite input from external 
actors, but this time they decided to hire a private consultancy firm that specialized in the use of theatre workshops. This firm took on the task of organizing three theatre workshops and a closing conference to be held at the Danish parliament. The four events were planned at a series of meetings between the firm and selected members of the Ethical Council. An increasing number of relevant and affected stakeholders were invited to participate in the three workshops starting with 15 and ending with 50 participants. 200 people including politicians, employees, patients and relatives and their organizations, attended the final conference. Although it is difficult to assess how much the innovation process affected the cultural images and role perceptions of the involved stakeholders, the process definitely affected the way of thinking within The Ethical Council. From having a scientific expert oriented approach to ethical questions, they began to view stakeholder experiences as relevant and valuable in considering ethical predicaments. After the closing conference the staff in the Ethical Council wrote a policy brief that was to be presented at a meeting in a relevant Parliamentary Committee. Much to the frustration of the Ethical Council this meeting was cancelled because very few politicians showed up, and the policy brief ended of having very limited effect on parliamentary policy making.

\section{Similarities and differences between the two cases}

Then, what have we learned about the potential impact that collaboration between politicians and stakeholders on policy innovation form the two experiments? Both studies show that collaboration can indeed contribute to the development of new policies and policy formats as well as to the development of new organizational, procedural and cultural innovations in political life. Moreover, however, the studies reveal a number of innovation barriers. In Albertslund the policy that was passed on to the City Council was very vague and is more correctly described as a policy vision than as a new innovative policy that provide added value in society by committing the politicians to 
realize specific political goals and strategies. The Ethical Council ended up with the problem that they failed to communicate the content of the new policy to the politicians, and again the policy innovation stranded at the stage of moving from innovative idea to realization.

Why did both experiments fail in transforming new innovative policy ideas developed through collaborative policy innovation between politicians and stakeholders into new political goals and strategies? The cause is to be fund in a failure to establish a productive balance between political leadership, competition and collaboration. In Albertslund the level of political leadership was well dosed. The City Council and the participating politicians functioned as convenors, facilitators and catalysts throughout the collaboration process, and the City Council was involved at regular intervals. The exercise of political leadership was also ensured because the mayor had the necessary NATO-resources to guide and steer the process. In comparison, very limited space was allowed for political competition between the different political parties in the City Council as well as in the collaboration process. The general idea was that disagreements between the parties should be kept off the agenda, and that prevented the politicians form testing their ideas and develop new viewpoints that took their political perspectives into account. As a result, the policy outcome did not really create changes in the political goals and strategies pursued by the individual parties in the City Council. This effort to seek consensus and suppress competition is most likely related to the fact that the experiment was carried out at the local level of governance in Denmark where consensus tends to be more dominant than at the national levels of government.

In the Ethical Council case, the level of conflict in the collaboration process was generally high. Raging verbal battles took place not only between different stakeholder groups but also between stakeholders and politicians and between politicians form different parties. These contestations 
contributed to creating creative destructions and the development of new ideas and little was done to create consensus. The weak point in this policy innovation process was a profound lack of political leadership that meant that neither the parliament nor the participating politicians felt any ownership of and/or responsibility for the fate of the policy outcome. The project was initiated by the Ethical Council and the role as convenor, facilitator and catalyst was performed by a consultancy firm. Moreover, none of the participating politicians possessed the NATO-resources needed to carry the new policy ideas into the parliamentary process with any strength. Ensuring strong political leadership of collaborative policy innovation processes is likely to be particularly difficult at the national level of governance because politicians who are able and willing to devote time to engaging in close interaction with relevant and affected stakeholders over a longer period of time are often in a marginal position in their respective parties.

\section{Conclusion}

Western liberal governments relentlessly seek ways to enhance the innovative capacity of the public sector, but there are few considerations regarding to that extent political life in Western liberal democracies fully exploits the available drivers of policy innovation. In this article, I have argued that there are a number of barriers to overcome in improving the policy innovation capacity of representative democracies. Barriers to policy innovation are not only found in the narrow perceptions of how to govern and who can govern, but also in the organizational, procedural and cultural political structures of representative democracy that provide ample space for political leadership and competition but does little to promote collaboration. The analyses of the two case studies indicate that an expansion of the opportunity for politicians to collaborate with relevant and affected actors in a shared attempt to develop new policies can contribute to promoting new 
innovative policy ideas. The studies also show, however, that the degree to which these ideas are transformed into new innovative policies authorized by elected politicians depends on how the collaboration processes are combined with political leadership and competition. In other words, my message is that at the macro level those who aim to promote the policy innovation capacity of representative democracies must reform political life in ways that establish a productive combination of these three important innovation drivers. At the micro-level those designing concrete situated policy innovation processes must do the same in ways that take the particular context and purpose into account.

\section{References}

Agger, A, and Sørensen, E, 2014, 'Enhancing Collaborative Policy Innovation: A Case Study from a Danish Municipality' in Ansell, C, and Torfing, J, eds, Public Innovation and Collaboration through Design, London, Routledge, 188-208.

Agger, A, Damgaard, B, Krogh, A, H, and Sørensen, E, eds, 2015, Collaborative Governance and Public Innovation in Northern Europe, London, Bentham Science Publishers.

Ansell, C, and Gash, A, 2012, 'Stewards, Mediators, and Catalysts: Towards a Model of Collaborative Leadership', The Innovation Journal, 17, 1, article 7.

Ansell, C, and Torfing, J, eds, 2014, Public Innovation and Collaboration through Design, London, Routledge. 
Bel, R, 2009, 'Leadership and Innovation: Learning from the Best', Global Business and Organizational Excellence, 29, 2, 47-60.

Borins, S, 2014, The Persistence of Innovation in Government: A Guide for Innovative Public Servants', The Innovation Series, IBM Center for the Business of Government, (www.businesofgovernment.org)

Bullinger, A.C., Neyer, A.-K., Rass, M. and Moeslein, K.M. (2010), 'Community-Based Innovation Contests: Where Competition Meets Cooperation', Creativity and Innovation Management, 19(3): 290-303.

Cain, B, E, Dalton, R, J, and Scarrow, S, E, Eds, 2003, Democracy Transformed? Expanding Political Opportunities in Advanced Industrial Democracies, Oxford: Oxford University Press.

Carstensen, H, V, and Bason, C, 2012, 'Powering Collaborative Policy Innovation: Can Innovation Labs Help?', The Innovation Journal: The Public Sector Innovation Journal, 17, 1, article 4.

Crozier, M, 2007, 'Recursive Governance: Contemporary Political Communication and Public Policy', Political Communication, 24, 1, 1-18.

Damanpour, F, 1991, 'Organizational Innovation: A Meta-Analysis of Effects of Determinants and Moderators', Academy of Management Journal, 34, 3, 555-590.

Dente, B, Bobbio, L, and Spada, A, 2005, 'Government or Governance of Urban Innovation?', DIPS, 162, 1-22. 
Deschampes, J, P, 2008, Innovation Leaders: How Senior Executives Stimulate, Steer and Sustain Innovation, Chichester, Wiley \& Sons Ltd.

Downs, A, 1967, Inside Bureaucracy, Boston, MA, Little, Brown.

Edquist, C, and Hommen, L, 1999, 'Systems of Innovation: Theory and Policy for the Demand Side', Technology in Society, 21, 1, 63-79.

Freeman, C, 1991, 'Networks of Innovators: A Synthesis of Research Issues', Research Policy, 20, $5,499-514$.

Goodin, R, E, and Dryzek, J, E, 2006, 'Deliberative Impacts: The Macro-politics Uptake of Minipublics', Politics and Society, 34, 2, 219-244.

Gray, B, 1989, Collaborating: Finding Common Ground for Multiparty Problems, San Francisco, Jossey-Bass.

Green, L, Howells, J, and Miles, I, 2001, 'Services and Innovation: Dynamics of Service Innovation in the European Union', Final Reprot, December 2001, PREST and CIRC, University of Manchester, England.

Hartley, J, 2005, 'Innovation in Governance and Public Service: Past and present', Public Money \& Management, 25, 1, 27-34.

Hartley, J, Sørensen, E, and Torfing, J, 2013, 'Collaborative innovation: A viable alternative to market-competition and organizational entrepreneurship?', Public Administration Review, 73, 6, 821-830. 
Hersey, M, ed, 2014, Guide to U.S. Political Parties, Thousand Oaks, CQ Press.

Hood, C 1991, 'A Public Administration for all Seasons?', Public Administration, 69, 1, 1-19.

Hood, C. 1986, The Tools of Government, Chatham, Chatham House Publishers.

Howarth, D, and Torfing, J, 2005, eds, Discourse Theory in European Politics, London, Palgrave.

Jessop, B, 2004, 'Multi-level Governance and Multi-level Metagovernance', In Bache, I, and

Flinders, M, Multi-Level Governance, Oxford, University Press, 50-74.

Kingdon, J. W. 1984, Agendas, Alternatives, and Public Policies, Boston, MA, Little, Brown.

Kramer, R, M, and Tyler, T, R, eds, 1996, Trust in organizations: Frontiers of theory and research, Thousand Oaks, CA, Sage.

Lijphart, A. 1977, Democracy in Plural Societies: A Comparative Exploration, New Haven, Yale University Press.

Lindblom, C, 1965, The Intelligence of Democracy, New York, The Free Press.

March, J, G, and Olsen, J, P, 1989, Rediscovering Institutions, New York: The Free Press.

Mayo, D, G, and Hollander, R, D, eds, 1991, Acceptable Evidence, Science and Values in Risk Management, Oxford, Oxford University Press. 
Nambisan, S, 2008, Transforming Government through Collaborative Innovation, Washington, DC: Harvard Kennedy School of Government.

Nickell, S, 1996, 'Competition and Corporate Performance', Journal of Political Economy, 104, 724-746.

Norris, P, 2011, Democratic Deficit: Critical Citizens Revisited, New York, Cambridge University Press

Osborne, D, and Gaebler, T, 1993, Reinventing Government: How the Entrepreneurial Spirit is Transforming the Public Sector, Reading, MA, Addison-Wesley.

Osborne, S. (2010). The New Public Governance?, New York: Routledge.

Osborne, S, and Brown, K, 2005, Managing Change and Innovation in Public Service Organizations, London, Routledge.

Pierson, P, 2000, 'Increasing Returns, Path Dependence, and the Study of Politics', American Political Science Review, 94, 2, 251-267.

Polsby, N, W, 1984, Political Innovation in America: The Politics of Policy Initiation, New Haven, CT, Yale University Press.

Roberts, N, C, and Bradley, R, T, 1991, 'Stakeholder Collaboration and Innovation', Journal of Applied Behavioural Science, 27, 2, 209-227.

Roberts, N, C, and King, P, J, 1996, Transforming Public Policy: Dynamics of Policy Entrepreneurship, San Francisco, CA, Jossey-Bass. 
Rogers, E, M, 1995, Diffusion of Innovation, New York, Free Press

Rowley, C, K, ed, 1987, Democracy and Public Choice, Oxford, UK, Basil Blackwell.

Sartori, G, 1987, The Theory of Democracy Revisited, Chatham, Chatham House Publishers, Inc.

Savigny, H, 2002, 'Public opinion, political communication and the internet', Politics, 22, 1, 1-8.

Schmitter, P,C, 1974, 'Still in the Century of Corporatism?', The Review of Politics, 36, 1, 85-131.

Schumpeter, J, 1946, Economic Theory and Entrepreneurial History, Cambridge, MA, Harvard University Press.

Sharpe, A, and Currie, I, 2008, Competitive Intensity as Driver of Innovation and Productivity Growth: A Synthesis of the Literature, Centre for the Study of Living Standards, Research Report no. $2008 / 3$.

Shein, E, 1992, Organizational Culture and Leadership: A Dynamic View, San Francisco, CA, Jossey-Bass.

Smith, G, 2009, Democratic Innovations, Cambridge, Cambridge University Press.

Stoker, G, 2006, Why Politics Matters: Making Democracy Work, Basingstoke, Palgrave Macmillan.

Sørensen, E, 2006, 'Metagovernance the Changing Role of Politicians in Processes of Democratic Governance', American Review of Public Administration, 36, 1, 98-114. 
Sørensen, E, and Torfing, J, 2011, 'Enhancing Innovation in the Public Sector', Administration and Society, 43, 8, 842-868.

Sørensen, E, and Waldorff, S, B, 2014, 'Collaborative policy innovation: Problems and potential', The Innovation Journal, 19, 3, article 2.

Teece, D, J, 1992, 'Competition, Cooperation, and Innovation', Journal of Economic Behaviour \& Organization, 18, 1, 1-25.

Torfing, J, 1999, 'Workfare with Welfare: Recent Reforms of the Danish Welfare State', Journal of European Social Policy, 9, 1, 5-28.

Torfing, J, Peters, B, G, Pierre, J, and Sørensen, E, 2012, Interactive Governance: Advancing the Paradigm, Oxford: Oxford University Press.

Tucker, R, C, 1995, Politics as leadership, Columbia, MO, University of Missouri.

US Government, 2012, Regulations.gov: Remaking Public Participation, The Open Government Partnership, http://www.whitehouse.gov/blog/2012/02/21/regulationsgov-remaking-publicparticipation.

Von Hippel, E, 2005, Democratizing Innovation, Cambridge, MIT Press.

Weber, M, 1947, The Theory of Social and Economic Organization, Ed, Parsons, New York, The Free Press. 